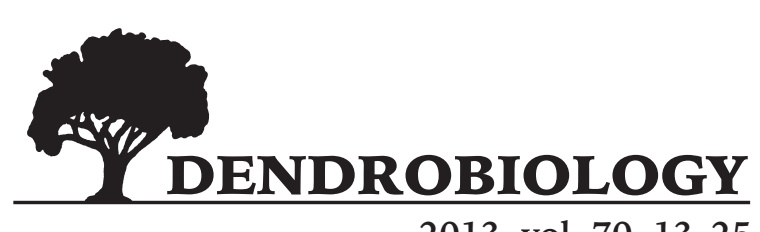

2013, vol. 70, 13-25

http://dx.doi.org/10.12657/denbio.070.002

\author{
Jinsong Wang, Juan Fan, Xiuhua Fan*, Chunyu Zhang, L. Wu, \\ Klaus v. Gadow
}

\title{
Crown and root biomass equations for the small trees of Pinus koraiensis under canopy
}

Received: 08 June 2012; Accepted 16 January 2013

\begin{abstract}
Estimation of tree biomass is an essential part of studies on carbon sequestration and cycling in forest ecosystem. Small trees grow in the understory and allometric development is different from that of mature trees. However, less attention has been paid to biomass estimates of small trees, especially in mixed forest where tree competition is intensive. Tree allometric equations at both branch level and at whole tree level were, thus, developed and compared for the small trees of Korean pine (Pinus koraiensis) in a mixed stand in northeastern China. At branch level, the best model for live branch biomass was one which used a combination of branch diameter, branch length, whorl position and relative branch depth. For needle biomass, the best model did not significantly improve the estimate with more variables. At whole tree level, stem diameter at breast height $(D B H)$ was a significant determinant of biomass for different components. Tree height did not significantly improve biomass estimation at all. Tree crown variables proved to be useful for estimating all biomass components except the fine roots. The variable measuring aboveground competition intensity was a significant negative determinant of biomass components except canopy biomass. Comparisons to published equations for the same species growing in Heilongjiang province in northeastern China and in central South Korea, were also presented. Both total aboveground biomass and belowground biomass in our study showed somewhat smaller values for a given diameter than the trees growing in other two places.
\end{abstract}

Additional key words: Branch level; Tree level; Allometric equation; Aboveground competition; Korean pine

Addresses: J.S. Wang, J. Fan, C.Y. Zhang, Key Laboratory for Forest Resource \& Ecosystem Processes of Beijing, Beijing Forestry University, Beijing 100083, P. R. China

L.Wu, Rothamsted Research, North Wyke, Okehampton, Devon EX20 2SB, UK

K. v. Gadow, Faculty of Forestry and Forest Ecology, Georg-August-University Göttingen, Büsgenweg 5, D-37077 Göttingen, Germany

X.H. Fan*, College of Science, Beijing Forestry University, Beijing 100083, P. R. China, Email: blfanxh@bjfu.edu.cn

*corresponding author: Juan Fan and Jinsong Wang contributed equally to this work

\section{Introduction}

Carbon storage in the forest plays a crucial role in the adjustment of atmospheric carbon dioxide and global carbon dynamics. Estimation of tree biomass is an essential part of studies on carbon sequestration and cycling in the forest ecosystem (Verónica et al. 2010). Moreover, information on the tree biomass is also important for evaluating plant adaptations to environment, for assessing ecological processes such as nutrient cycles, forest productivity, fuel potential and competition in communities and for studying sus- 
tainable management of forest resources (Salis et al. 2006; Zianis et al. 2010).

Quantifying tree biomass by direct harvesting and weighing is very costly and impractical for large-scale use (Quint and Dech 2010). Therefore allometric equations are commonly used as a non-destructive method alterative in which biomass of different components is estimated based on easily quantifiable tree attributes (Jagodziński and Kałucka 2008; Sampaio et al. 2010).

Numerous easily measurable variables have been used to develop and compare allometric equations. Independent branch-level variables are generally simple morphological branch characteristics such as branch diameter, branch length and relative branch depth. Tree-level variables are commonly tree diameter at breast height, tree height, tree age, and/or crown attributes such as crown length, crown ratio and crown area (e.g., Ter-Mikaelian and Korzukhin 1997; Xiao and Ceulemans 2004). Thus, it is necessary to apply and assess these different variables for developing a reliable allometric equation, which is capable of estimating above- and below-ground biomass components for a given target species.

Similarly, less attention has been paid to biomass estimation for saplings or small trees. Small trees grow in the understory in the forest, intraspecific and interspecific competitions are always intensive due to lack of available radiation. Thus, allometric development in the small trees is different from that of mature trees. This could eventually be important for modeling stand development and has indeed often been neglected. Numerous published studies have reported the effect of aboveground competition on small trees growth (Mäkelä and Vanninen 1998; Watt et al. 2003). We are not aware of any investigation that deals with aboveground competition influences biomass estimates for the small trees. Additionally, in terms of stand-level total biomass, proportions of smaller trees are generally not as large as those of larger individuals, except for specific forest types or conditions. Nevertheless, small trees are an important composition of many forests and even biomass return rate is higher than overstorey. Thus, excluding them may cause serious underestimation of the whole stand biomass and it is logical to pay attention to their contribution to total forest biomass.

Korean pine (Pinus koraiensis) grows in the Amur and Eastern maritime provinces of Russia, Korea, the northeast of China, and sporadic areas on the Japanese islands of Honshu and Shikoku. Korean pine is also a major plantation tree species in northeastern China as well as in Korea because of highly valued wood products and nuts. It prefers a humid and warm climate and also likes acid soils with good drainage and aeration. Young trees favor light, and light requirement increase with age. To the best of our knowledge, a limited number of studies have been undertaken concerning allometry of Korean pine, except the work by Wang (2006; involving 10 trees) and the analysis by Son et al. (2001; involving 20 trees) in the mixed forests. Neither of these studies presents allometric relationships at branch level and comparisons of allometric equations derived using different independent variables.

The objectives of this paper were 1) to develop allometric relationships at branch and at whole tree levels, which are capable of estimating different above- and below-ground biomass components for the small trees of Korean pine under canopy; 2) to test if branch diameter at branch level or breast height diameter at whole tree level is sufficiently reliable for biomass component estimates; 3 ) to compare the results of this study with other published equations and then estimate total stand biomass as well as the contribution of the small trees.

\section{Materials and methods}

\section{Study site}

The study site is situated in the vicinity of Guangming Forestry Center in Changbaishan Nature Reserve in northeastern China $\left(42^{\circ} 21^{\prime} \mathrm{N}, 128^{\circ} 08^{\prime} \mathrm{E}, 748 \mathrm{~m}\right.$ a.s.l.). The study area is a natural secondary forest dominated by P. koraiensis, Abies nephrolepis, Quercus mongolica, Tilia amurensis, Fraxinus mandshurica and Acer mono in association with other subcanopy tree species. It represents the typical forest type and landscape of deciduous broad-leaved and coniferous mixed forests. The climate in this region has been described as continental mountainous and monsoon-affected with an annual average temperature of $3.6^{\circ} \mathrm{C}$ (January $-15.4^{\circ} \mathrm{C}$ and August $19.6^{\circ} \mathrm{C}$ ). The annual mean precipitation is $707 \mathrm{~mm}$. The distribution of the precipitation over the year is relatively uneven. Relatively wet and dry seasons occur from June to August, and from September to May of the following year, respectively. The parent material is granite bedrock and the soil is classified as a brown forest soil, with a depth ranging from 20 to $100 \mathrm{~cm}$. The topography is flat and slope is generally less than five degrees.

\section{Field sampling and data collection}

A permanent research plot covering an area of 200 $\mathrm{m} \times 260 \mathrm{~m}$ was established at the site in July 2007 to represent $P$. koraiensis, Abies nephrolepis and deciduous broad-leaved species dominated forest. The plot was further subdivided into 130 contiguous square subplots with $20 \mathrm{~m} \times 20 \mathrm{~m}$ each. In each subplot, the species of all live and dead trees with their diameters at the breast height $(D B H)$ exceeding $1 \mathrm{~cm}$ were identified. The $D B H$, tree height and crown dimensions of each tree were measured and recorded. With a stem 
density of 2831 stems/ha and a total basal area of $32.07 \mathrm{~m}^{2} /$ ha in the plot, the density of Korean pine is 149 stems/ha and total basal area is $2.32 \mathrm{~m}^{2} / \mathrm{h}$. The upper height of the competing trees ranges from 30 to $35 \mathrm{~m}$. A histogram of total recorded Korean pine in the plot is presented in Fig. 1. The DBH of most Korean pine is less than $10 \mathrm{~cm}$. We define a "small tree" as one with a $D B H$ less than $10 \mathrm{~cm}$ and a height less than $10 \mathrm{~m}$. A moderate selective felling was carried out in 1953.

Ten small trees with $D B H$ between 1.9 and $9.7 \mathrm{~cm}$ were selected in the research plot for a destructive measurement of above- and below-ground biomass. Trees with severe defects were not included. Each Korean pine subject tree was located at the centre of a circular plot. Each plot had a $10 \mathrm{~m}$ radius and constituted the 'competition zone' for the subject tree. All trees with $D B H$ s exceeding $5 \mathrm{~cm}$ in this 'competition zone' were selected as competitors, and their DBHs and distances to the subject tree were assessed. The study was carried out during two months, between June and August 2009.

Stems were cut at ground level. Dead branches were collected first, followed by the measurement and recording of total tree height $(H)$, height to the lowest live branch $(L C H)$, live crown length $(C L)$. Crown width from south to north $(C S N)$ and crown width from east to west (CEW) measurement and recording followed immediately. The number $(n)$ of live whorls was recorded as well. Following Xiao and Ceulemans (2004), whorl position (WP) $=1$ is defined as the first live whorl from the top of the crown, ranging down until $W P=n$ which is the lowest live whorl. Each branch height $(H B)$ was measured to the nearest $0.05 \mathrm{~m}$ using a tape measure that was stretched vertically along the main stem of each sample tree.

The live crown was then divided into three sections of equal length (top, middle, and bottom). The fresh biomass of stems, live branches, and needles from each section was weighed using an electronic scale to the nearest $1 \mathrm{~g}$ for each sample tree. From each component, approximately $50-100 \mathrm{~g}$ of fresh mass was randomly sampled and the dry mass of each component was calculated using the dry/fresh ratio of each component sample after oven-drying to a constant mass at $80^{\circ} \mathrm{C}$.

Two or three branches were selected as sub-samples from each section in each sample tree. Each branch sub-sample was separately labeled and transferred to the laboratory. Branch diameters $(B D)$ at about $2 \mathrm{~cm}$ from the bole were measured with an electronic caliper to the nearest $0.01 \mathrm{~cm}$ and branch lengths $(B L)$ were measured to the nearest $0.1 \mathrm{~m}$ with a tape from the main stem to the farthest foliated section of the branch sub-sample. The relative depth (RBD) of each branch sub-sample in the live crown was defined as $(H-H B) /(H-L C H)$ for the following analysis. All needles were removed from each branch sub-sample, and the fresh mass of live branch and needles was measured to the nearest $0.001 \mathrm{~g}$ with an electronic scale. The dry mass of live branches was determined after oven-drying at $80^{\circ} \mathrm{C}$ for 5 days, and for all needles (3 days) of each branch sub-sample. A total of 79 branch sub-samples were selected to develop allometric relationships for estimating live branch and needle biomass at branch level.

The entire root system of each sample tree was carefully excavated by hand to avoid disrupting the finest roots. We collected as much fine root biomass for each tree as possible by cautiously digging out each root by hand. The task was facilitated by shallow-rooting habit of Korean pine and by favourable soil properties. The entire root was delivered as a whole to the laboratory, washed free of soil and then sorted into fine roots $(\leq 5 \mathrm{~mm})$ and coarse roots $(>5$ $\mathrm{mm}$ ) using a electronic caliper, following the method applied by Cheng et al. (2005). Dry mass was determined after oven-drying at $80^{\circ} \mathrm{C}$ for 3 days (fine roots) and 10 days (coarse roots). To estimate the age $(A)$ of each sample tree, the annual rings on the basal disk were counted using Lintab 5 system (Rintech, Heidelberg, Germany).

\section{Data analysis}

For each sample tree, competition intensity $(C I)$ from neighbouring trees was computed using the Iterative Hegyi Index. This Index has been found superior to other competition indices requiring tree coordinates. Indices which use simulated crown shading, available radiation and other techniques were found less effective in explaining tree growth. A possible reason for the explanatory power of the Iterative Hegyi Index is the fact that it a) uses a dynamic competition zone and b) differentiates between 'active' and 'passive' competitors (Lee and Gadow 1997). Detailed descriptions of the calculation method can be found in Wang et al. (2011). For these reasons, the Iterative Hegyi Index was chosen to analyze the competition intensity in this study.

A general non-linear allometric equation was used to calculate live branch and needle biomass (Xiao and Ceulemans 2004):

$$
Y=a_{0} X_{1}^{p_{1}} X_{2}^{p_{2}} X_{3}^{p_{3}} \ldots X_{n}^{p_{n}} \theta
$$

where $Y$ is needle or live branch biomass, $X i$ are independent variables, $a_{0}-p_{n}$ are model coefficients and $\theta$ represents the multiplicative error term. Eq. 1 can be converted into logarithmic form so that, a linear regression can be used to estimate the coefficients:

$$
\begin{aligned}
& \ln Y=p_{0}+p_{1} \ln X_{1}+p_{2} \ln X_{2}+ \\
& p_{3} \ln X_{3}+\ldots p_{n} \ln X_{n}+\varepsilon
\end{aligned}
$$


where $p_{0} \ln a_{0}$, and $\varepsilon=\ln \theta$. The logarithmic transformation of a dependent variable can cause a bias when reverse transformation is operated (Zar 1996). Thus, a correction factor $k$ was introduced:

$$
k=\frac{\sum_{i=1}^{n} Y_{i}}{\sum_{i=1}^{n} e^{\ln Y i}}
$$

where $n$ is the sample size, $Y_{i}$ and $\hat{Y}_{i}$ represent the observed and predicted values. This method ensures that the mean predicted value is equal to the mean observed value. Hence, an unbiased estimate of $Y$ is given as:

$$
\hat{Y}=k \times \exp \left(p_{0}+p_{1} \ln X_{1}+p_{2} \ln X_{2}+p_{3} \ln X_{3} \ldots+p_{n} \ln X_{n}\right.
$$

We developed these equations using $B D, B L, W P$ and $R B D$ as independent variables, to identify an equation suitable for estimating biomass of live branches and needles at branch level. Significance was evaluated at the $P=0.05$ and 0.01 probability levels. All parameters were tested for significance.

Eq. 2 was also used for estimating total tree biomass and biomass of stems, live branches, needles, and roots at whole tree level. For each biomass component three equations were developed with different combination of independent variables: (i) $\mathrm{DBH}$, (ii) $D B H$ and $H$, (iii) the combination of $D B H, H, A, C L$, CSN, CEW and CI, using stepwise regression and a significance level of $P=0.15$.

The criterion used for the selection of the best equation was adjusted coefficient of determination $\left(R_{\text {adj }}^{2}\right)$, root mean square error (RMSE), mean bias $\left(B_{i a s}\right)$, fit index $(F I)$, Akaike's information criterion (AIC). RMSE, $B_{i a s}, F I$ are expressed in Eqs. 5-7. In addition, percentage RMSE and MPE expressed in Eq. 8 and 9 are used to indicate expected estimation error and mean relative prediction error respectively (Hosoda and Iehara 2010).

$$
\begin{gathered}
R M S E=\sqrt{\sum_{i=1}^{n}\left(Y_{i}-\hat{Y}_{i}\right)^{2} / n} \\
B_{i a s}=\sum_{i=1}^{n}\left(Y_{1}-\hat{Y}_{i}\right) / n \\
F I=1-\sum_{i=1}^{n}\left(Y_{i}-\hat{Y}_{i}\right)^{2} / \sum_{i=1}^{n}\left(Y_{i}-\bar{Y}_{i}\right)^{2} \\
\operatorname{RMSE}(\%)=\sqrt{\sum_{i=1}^{n}\left(\left(Y_{i}-\hat{Y}_{i}\right) / Y_{i}\right)^{2} / n \cdot 100}
\end{gathered}
$$

$$
M P E=\frac{100}{n} \sum_{i=1}^{n}\left|Y_{i}-Y i\right| Y_{i}
$$

In Eq. 7, $\bar{Y}$ is average observed values for each biomass component. Percentage RMSE and MPE are indices of precision mainly expressed by estimating error. Bias is an index of unbiasedness of estimation. FI is analogous to the coefficient of determination in ordinary linear regression. All statistical analyses were performed using the R version 2.12.1 statistical software (R Development Core Team 2010).

\section{Results}

\section{Estimation of live branch and needle biomass at branch level}

Total dry matter of branch sub-samples $(\mathrm{N}=79)$ ranged from 0.12 to $198.29 \mathrm{~g}$ with a mean equal to $33.90 \mathrm{~g}$ and associated standard error of $4.41 \mathrm{~g}$. For needles, the total dry mass spanned from 1.30 to $73.52 \mathrm{~g}$ with an average value of $21.50 \mathrm{~g}$ and standard error equal to $2.07 \mathrm{~g}$. The allometry of observed live branch and needle biomass versus $B D$, as well as a residual plot is shown in Fig. 2. All relationships were highly significant $(P<0.001)$. Most of the variability was explained for live branch biomass $\left(R_{a d j}^{2}=0.946\right)$. Some slightly weaker match was found for needle biomass $\left(R_{a d j}^{2}=0.721\right)$.

Different allometric equations were established to predict live branch and needle biomass, using $B D, B L$, $W P$ and RBD (Table 1). All relationships involving biomass estimates with different variables were highly significant for live branches and needles $(P<0.001)$. Compared with the equation using single variable $B D$, a considerable reduction in RMSE, MPE as well as AIC and an increase in $R_{a d j}^{2}$ and FI was found when using additional variables to predict live branch

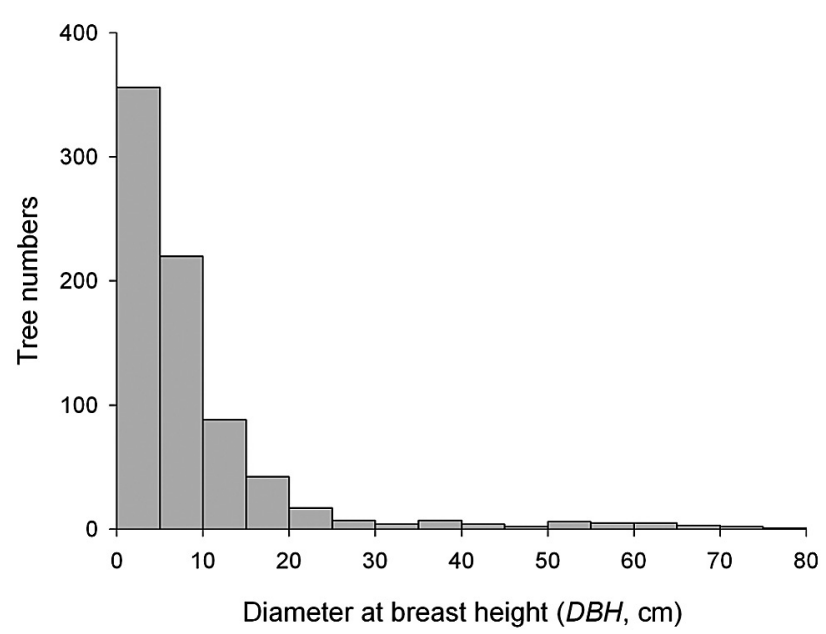

Fig. 1. Frequency histogram of recorded Korean pine trees in the research plot in Changbaishan Nature Reserve in northeastern China 

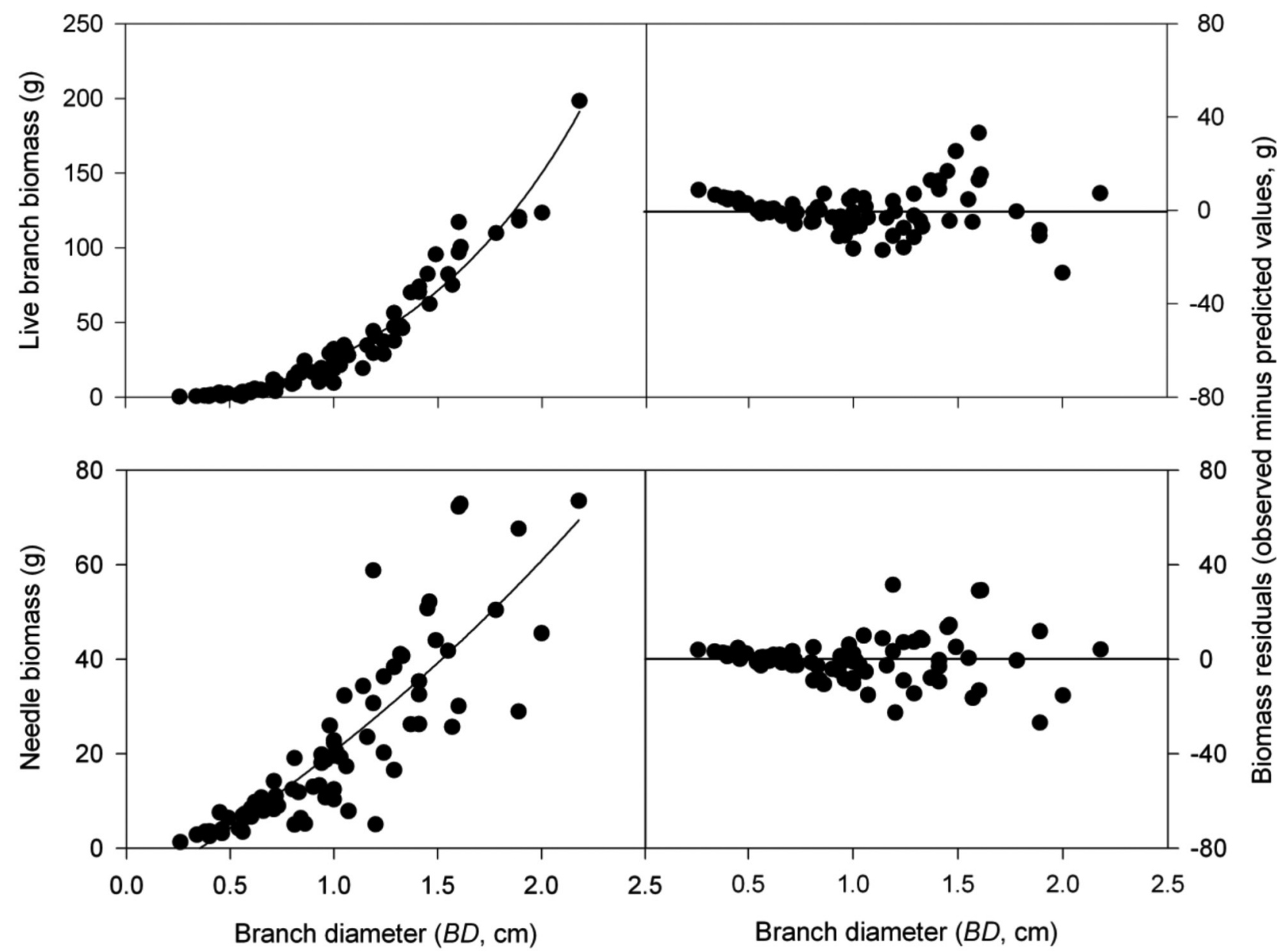

Fig. 2. The allometry of observed live branch and needle biomass versus branch diameter as well as a residual plots at branch level

biomass. The RMSE, MPE, AIC values and absolute Bias were the smallest, and FI was the highest in the equation using four variables for live branch biomass. Even if the number of parameters was increased, it was judged that the equation using four variables would be the best model. In addition, the variables $B D, B L$ and $R B D$ showed a significantly positive $(P<0.001)$ while WP showed a significantly negative correlation with live branch biomass $(P<0.05)$.

Estimates of the needle biomass were not as good when compared with those of live branch biomass, with the $R_{a d j}^{2}$ values of different equations ranging between 0.82 and 0.84 . The relationship of biomass with three variables $(B D, B L, W P$ or $B D, B L, R B D)$ produced the best fit for needle biomass estimates. Interestingly, the variables $B D$ and $B L$ showed a positive correlation with needle biomass, while WP or $R B D$ showed a significantly negative correlation with needle biomass $(P<0.001)$.

The relationship between observed and predicted biomass components, estimated either by the $B D$ model or the best model for live branch and needle biomass is shown in Fig. 3. The slope of the regression (1.121) for the $B D$ model with correction factor indi- cates a slight overestimation for live branch biomass, whereas, the slope of 1.002 for the best model showed that the predicted values were almost identical to the observed values and matched very well. A considerable underestimation for the $B D$ model or the best model is presented in Fig. 3 in the case of needle biomass. Additionally, the slope of the regression for the best model was basically identical to that of the BD model.

\section{Estimation of biomass components at whole tree level}

The observed values of different biomass components plotted against $D B H$ and $H$ are shown in Fig. 4. Individual biomass components showed a significant exponential relationship for both the $D B H$ and $H$. The best fit was obtained for the biomass components of stems and roots, which could explain most of the total variation in the observed data.

Different allometric equations for biomass components, except dead branches, were developed and compared using the independent variables (Table 2). Separately, all biomass equations were highly significant for individual components $(P<0.001)$. The fit using the single variable $D B H$, explained most of the 


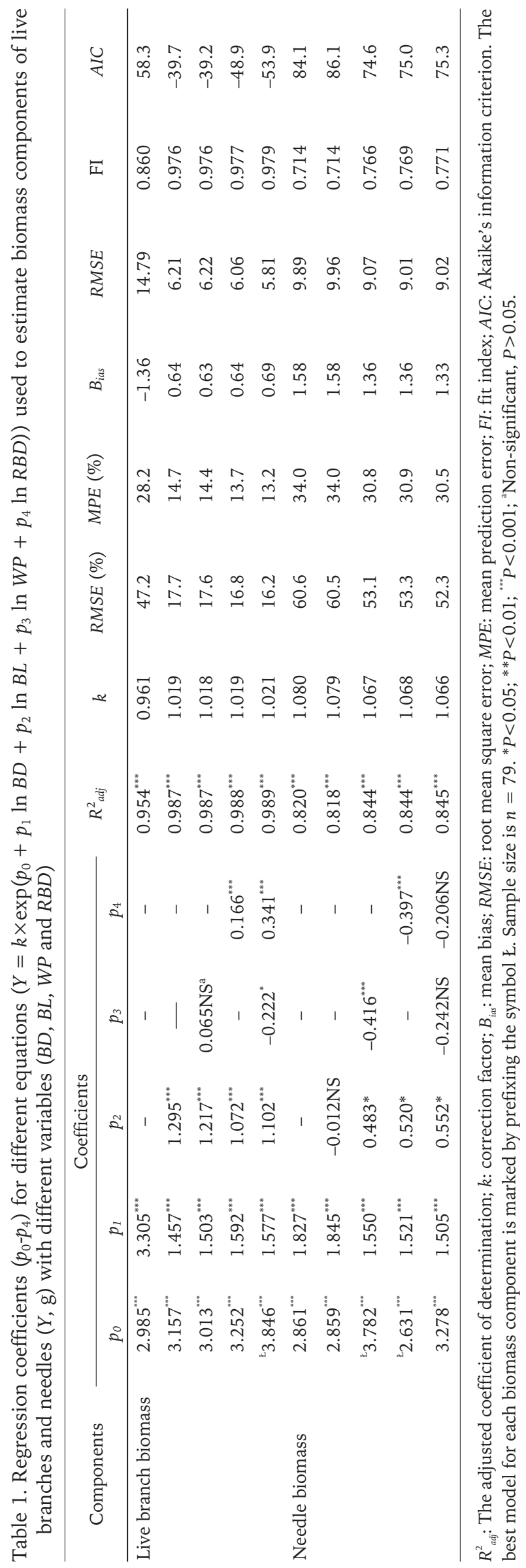



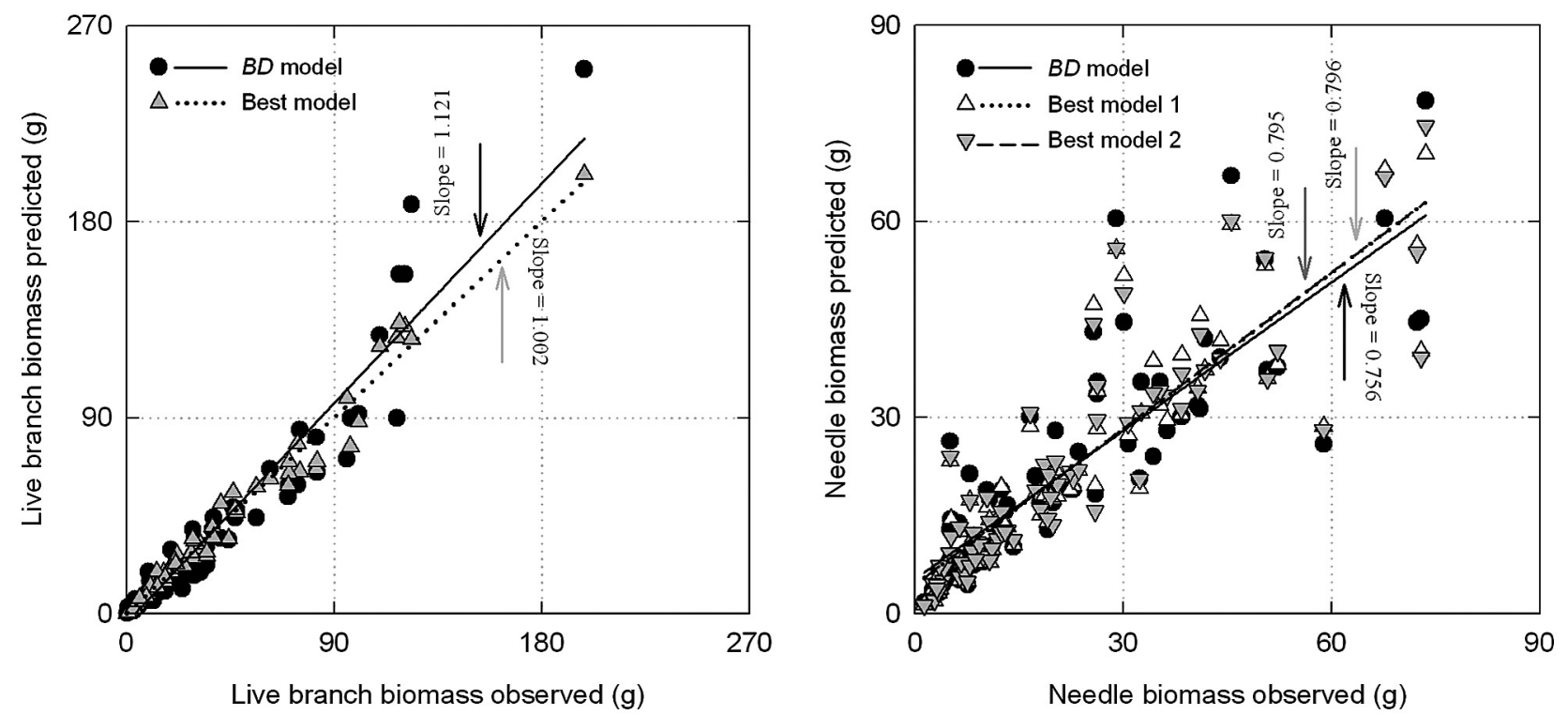

Fig. 3. The relationship between observed and predicted values estimated either by the $B D$ model or the best model for live branch and needle biomass at branch level. Best model 1 referred to the regression using variables of $B D, B L, W P$ and best model 2 the regression using variables of $B D, B L$, and $R B D$ for needle biomass from Table 1

total variation in the observed data involving biomass components of stems and total aboveground. A marginally weaker fit was found for the components of coarse roots and total belowground $\left(R_{a d j}^{2}\right.$ about $\left.97 \%\right)$. Somewhat weaker fits were found for the components of live branches, needles, and fine roots, with $R^{2}{ }_{a d j}$ values ranging from $84 \%$ to $94 \%$.

Table 2 shows that the inclusion of $H$ and other independent variables generally improved the fit for biomass components, when compared with the results of using only $D B H$. Tree height helped explain the variation by an additional $8 \%$ for the needle biomass, and this result was striking. In terms of MPE, RMSE as well as AIC, the values were all largely reduced when $H$ was included in the needle biomass es- timates. However, it did not improve biomass estimates for other components.

The best models for each biomass component are also listed in Table 2. The information on crown characteristics helped to improve the estimates for almost all biomass components except the fine roots. CSN and $C E W$ significantly affected biomass estimates of live branches and needles. RMSE and MPE in the best models for live branches and needles were the smallest, mean bias was closer to zero, and FI was the highest. AIC was also much smaller in the best models than in the $D B H$ model. Interestingly, $C S N$ exhibited a significantly positive and CEW showed a significantly negative correlation with biomass components in the best models. It also can be noted that $C L$ significantly
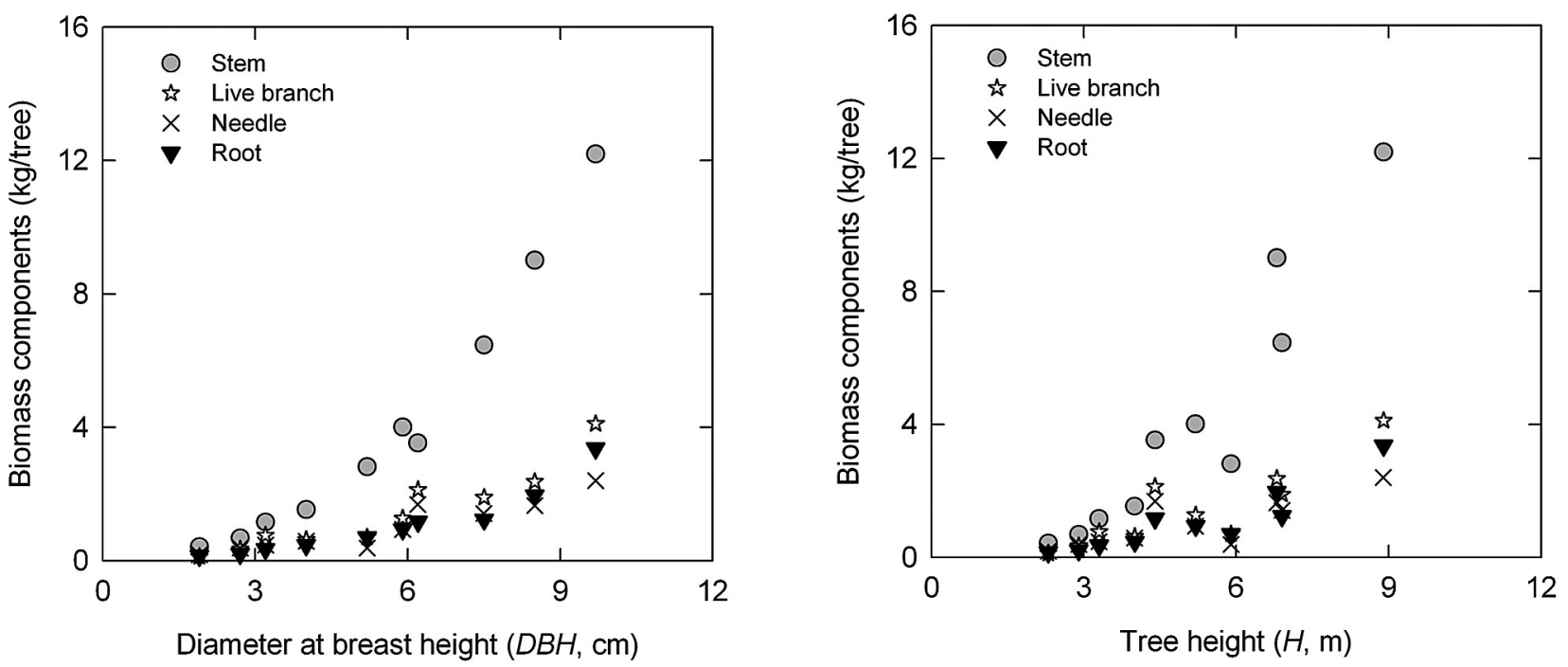

Fig. 4. The observed values of different biomass components plotted against $D B H$ and $H$. Root biomass included fine root biomass and coarse root biomass 


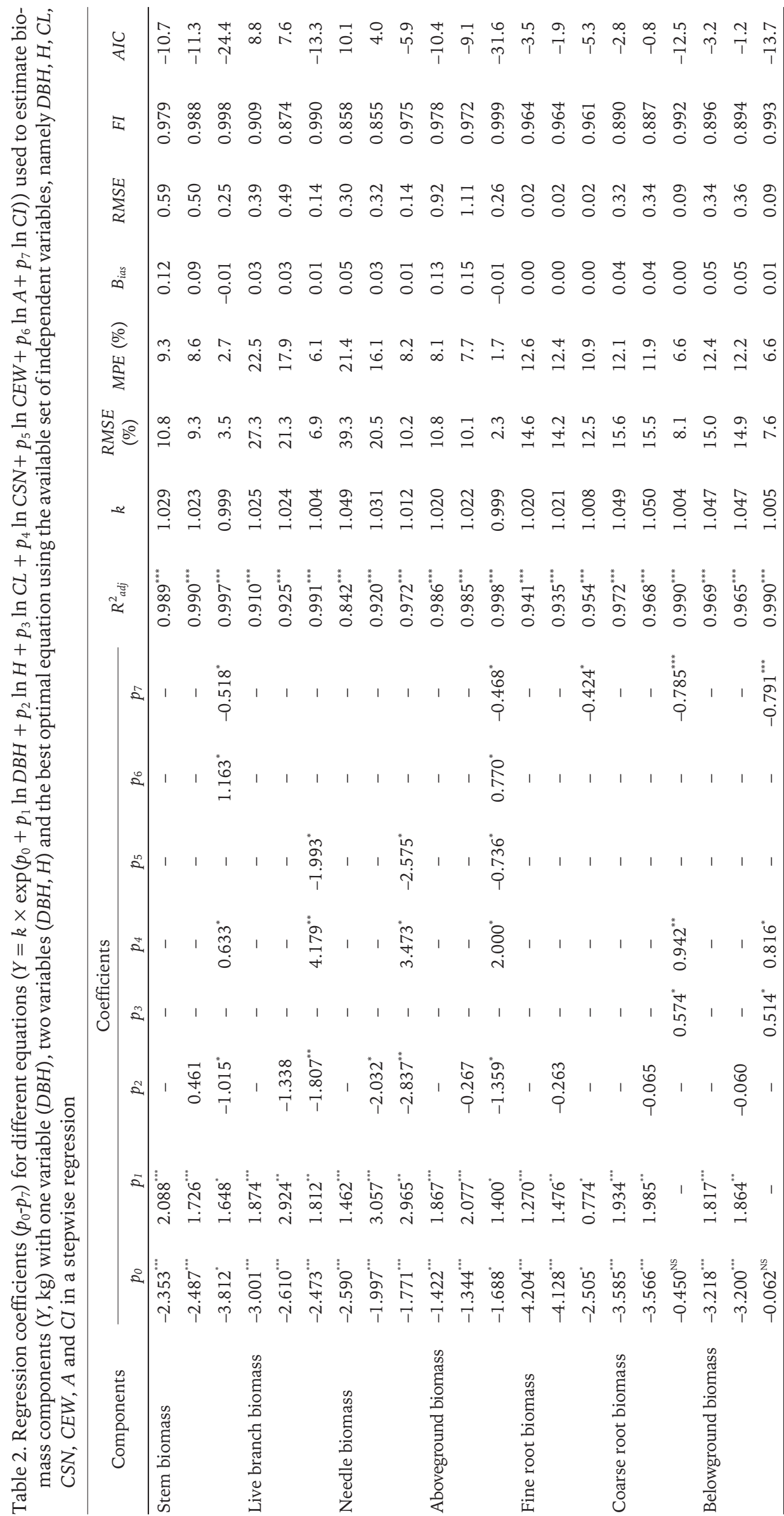


Table 3. Biomass estimates of different components in the research plot by applying allometric equations for the small trees with $D B H \leq 10 \mathrm{~cm}$ in this study and equations for trees with $D B H>10 \mathrm{~cm}$ cited from Wang (2006). Value in parenthesis is a relative proportion (\%) of each component biomass to total stand biomass

\begin{tabular}{lccc}
\hline \multirow{2}{*}{ Components } & \multicolumn{3}{c}{ Biomass $\left(\mathrm{Mg} \mathrm{ha}^{-1}\right)$} \\
\cline { 2 - 4 } & $D B H \leq 10 \mathrm{~cm}$ & $D B H \geq 10 \mathrm{~cm}$ & Total \\
\hline Stems & $1.72(2.70)$ & $31.27(49.02)$ & $13.99(51.72)$ \\
Live branches & $0.60(0.94)$ & $13.02(20.41)$ & $2.86(4.48)$ \\
Needles & $0.44(0.69)$ & $2.42(3.79)$ & $49.47(77.55)$ \\
Total aboveground & $2.76(4.33)$ & $46.71(73.22)$ & $0.06(0.09)$ \\
Fine roots & $0.06(0.09)$ & $-($ not measured) & $14.26(22.36)$ \\
Coarse roots & $0.38(0.60)$ & $13.88(21.76)$ & $14.32(22.45)$ \\
Total belowground & $0.44(0.69)$ & $13.88(21.76)$ & 0.29 \\
Belowground/aboveground & 0.16 & 0.30 & $63.79(100)$ \\
\hline Total tree & $3.20(5.02)$ & $60.59(94.98)$ & \\
\hline
\end{tabular}

affects biomass estimates of coarse roots and total belowground.

$A$ and $C I$ usually improved equation fit but in different ways. $A$ was a significant determinant of stem biomass and total aboveground biomass. Disregarding tree age may give slightly biased estimates. CI seemed to be very important for biomass estimates except canopy biomass. And $\mathrm{CI}$ exhibited a significant negative correlation with biomass components.

Due to the fact that the improvement of evaluation indices for live branches and needles in the best model is the greatest, these two components were selected to quantify the difference between biomass estimates from the $D B H$ model and from the best model. A small underestimation either for live branch or needle biomass was presented for both the $D B H$ model and the best model. The slope of the regression for the $D B H$ model was 0.895 for live branch biomass and 0.827 for needle biomass, whereas, the slope of 0.970 for live branch biomass and that of 0.952 for needle biomass showed that the predicted values estimated by the best model were almost identical to the observed values and fitted very well.

\section{Stand biomass and contribution of small trees}

Due to similar study site as well as sample trees were mainly composed of larger trees $(D B H>10 \mathrm{~cm})$, biomass equations cited from Wang (2006) in Heilongjiang province in northeastern China and biomass allometry in this study were used to estimate larger trees and smaller trees biomass, respectively in the stand (Table 3). Our estimated total stand biomass is $63.79 \mathrm{Mg} \mathrm{ha}^{-1}$. The relative contribution of smaller trees to total stand biomass is about $5 \%$. The belowground to aboveground biomass ratio is estimated at 0.16 for smaller trees and 0.30 for larger trees.

\section{Discussion}

\section{Biomass allometric equations at branch level}

Branch and foliage quantity within the canopy play an important role in the ability of a forest to assimilate carbon, since crown is the location of the physiological processes (Crecente-Campo et al. 2009). We have shown in the present study that branch attributes such as branch diameter, branch length, whorl position and branch depth were found very appropriate for estimating live branch and needle biomass. Our findings agree in principle with earlier studies of Scots pine (Xiao and Ceulemans 2004), Loblolly pine (Blazier et al. 2002) and Douglas-fir (Ishii and Wilson 2001).

At branch level, needle biomass was more difficult to estimate relative to live branches, probably due to the fact that needles are highly sensitive to light, water and nutrients. In addition, needle vitality is influenced by their location on the branch and within the crown (Wang 2006). If this is true, tree size distribution, species mixture and stand density should affect the amount of branch and foliage biomass (Grote and Reiter 2004). The best equations showed that live branch and needle biomass increased with branch diameter and branch length, but that live branch biomass increased and needle biomass decreased with relative branch depth for a given branch diameter and branch length. The most likely reason for this finding is the fact that light availability decreases with crown depth (Brix 1981), and that needle growth is strongly affected by the reduction of the available radiation (McCrady and Jokela 1996). Live branch growth is less affected by reduced light availability, as the cumulative time for branch biomass accumulation increases with crown depth (Xiao and Ceulemans 2004). Obviously, less foliage is sustained on live branches at the crown base, because of restricted light 
availability, although branch diameter is greater. Our findings are similar to those of Hepp and Brister (1982) who found that the maximum dry weight of an individual branch for Loblolly pine occurs at $20 \%$ of the crown length up from the base of the live crown.

As for live branch biomass, the best model was the one that used a combination of branch diameter, branch length, whorl position and relative branch depth. Though the simpler BD model slightly overestimates live branch biomass, it may be enough to be used at branch level when considering the difficulties of acquiring basic data. However, a considerable underestimation in needle biomass is presented in both $B D$ model and the best model. Additionally, the slope of the regression for the best model was basically identical to that of the $B D$ model. This indicated that the best model including more variables did not significantly improve needle biomass estimates. This implies that the simple $B D$ model may be a practical compromise for predicting needle biomass. It will slightly underestimate this component, but requires less field measurements.

\section{Biomass allometric equations at whole tree level}

The majority of previous biomass studies for different species focused on tree level allometric equations which are commonly used to estimate biomass of aboveground components in combination with specific tree characteristics (e.g., Son et al. 2001; Basuki et al. 2009). Only a few studies presented allometric equations involving belowground components (Van Lear and Kapeluck 1995; Wang 2006). In addition, allometric equations have rarely been used for fine root $(\leq 5 \mathrm{~mm})$ biomass due to the technical difficulties (Vanninen and Mäkelä 1999; Xiao and Ceulemans 2004). Our allometric equations, using easily measurable tree characteristics, estimate the biomass of above- and below-ground components for the small trees of Korean pine with high accuracy. We found that $\mathrm{DBH}$ was an important independent variable when estimating the different biomass components. This confirms previously published findings (e.g., Johansson 1999; Xiao and Ceulemas 2004).

Several other studies discussed the inclusion of tree height as a second variable in allometric equations, e.g. for boreal (Cienciala et al. 2006; Wagner and Ter-Mikaelian 1999) and tropical tree species (Cole and Ewel 2006). Wagner and Ter-Mikaelian (1999) found that the inclusion of tree height as a second variable improved the prediction of stem biomass but not the estimation of root biomass for white pine (Pinus strobes L.) seedlings. Cienciala et al. (2006) reported that the inclusion of height gave improved estimates of aboveground biomass of Scots pine across central Europe. In our study, using tree height as a second independent variable did not significantly improve the estimation, except in the case of needle biomass. This is probably caused by a high collinearity between breast height diameter and tree height, due to the high correlation between these two variables (0.96). Probably for this reason, tree height was rarely used in similar studies (Pastor et al. 1984). Height measurements are time-consuming and less accurate than $\mathrm{DBH}$ mesurements. In addition, adding tree height may introduce propagated variance due to a cumulative variance caused by height measurement errors (Mowrer and Frayer 1986; Wang 2006).

The contribution of additional independent variables was evaluated by analysing the changes of evaluation indices. Additional tree crown attributes proved to be useful for estimating all biomass components except fine roots. Crown width is an important determinant of canopy biomass and our best estimates of live branch and needle biomass were both based on crown width. The amount of available light absorbed by canopy may depend on its orientation, especially in northern regions. The amount of solar radiation is greater coming from a southerly direction and canopy biomass may be greatly affected by the orientation of the crown. Thus, the south-northerly crown width showed a positive correlation with live branch and needle biomass. Conversely, the east-westerly crown width was negatively correlated with canopy biomass.

Factors such as stand age, soil condition, topography, and disturbance may affect tree allometry and biomass partitioning patterns (Jenkins et al. 2003; Petersen et al. 2008). Aboveground tree size has a disproportionate advantage in competing for light, which is due to the fact that aboveground competition is asymmetric (Weiner 1990), while belowground competition appears size-symmetric (Casper and Jackson 1997). To our knowledge, this study is the first trial which evaluates the effect of aboveground competition on the tree allometry. Our findings suggest that competition intensity is a significantly negative determinant of biomass components except canopy biomass. The most likely reason for this result maybe the effects of competition on biomass partitioning of above- and below-ground components and thus on the tree biomass allometry. Similar to this finding, Petersen et al. (2008) reported young Douglas-fir growing in areas with and without competition. They found that allometric equations were very different for estimating biomass of this species due to the fact that trees growth without competition had higher leaf area-DBH correlations than that with competition.

Allometric equations using many independent variables may reduce the prediction bias to a certain extent, but it is always desirable to keep the set of 
variables as small as possible to reduce the variability of estimation (Wirth et al. 2004). The selection of a "best" biomass equation depends on the practical considerations, especially the availability of specific independent variables (Cienciala et al. 2006). Statistically, the more independent variables are included, the more precise estimates are obtained. However, the difficulties of acquiring basic data during field inventories should not disregarded. As mentioned before, it is necessary to find a balance between statistical significance and intended use in order to predict tree biomass better.

Based on the comparisons of different biomass models using a range of evaluation indices, we recommend that branch diameter at branch level and breast height diameter at whole tree level be selected as simple and reliable independent variables. More precise estimation of biomass components such as live branches and needles require crown variables.

\section{Comparisons to other available equations}

Our biomass estimates were also compared with those other studies of Korean pine. For this purpose, we selected published equations from the biomass dataset presented by Son et al (2001) on individual trees with $D B H$ 's ranging from about 8 to $36 \mathrm{~cm}$ in central South Korea and by Wang (2006) with DBH's ranging from 2.4 to $30 \mathrm{~cm}$ in Heilongjiang province in northeastern China (Fig. 5). Both equations in central South Korea and in Heilongjiang province used the base 10 logarithm, which were both transformed to the natural logarithm in accordance with this study and could easily be compared. Total aboveground biomass in our study was smaller for a given diameter than the estimates for the trees sampled either in Heilongjiang or in central South Korea. The slope of the regression for the total aboveground biomass was 1.867 in our study, whereas it was 2.144 in Heilongjiang province and 2.386 in central South Korea. Similarly, total belowground biomass in our study was also somewhat smaller for a given diameter than the estimates for the trees grown in Heilongjiang province. Belowground biomass components were not available from the Korean pine study in central South Korea.

Korean pine in this study has much lower aboveground and belowground biomass values for a given $\mathrm{DBH}$ than the trees grown in other two places. These differences may be the results of different soil and climatic conditions, such as temperature, water and soil nutrients. However, it is more likely that the differences in the allometric relationships are due to the differences in tree sizes. As trees in our study were restricted to the small trees with $D B H \leq 10 \mathrm{~cm}$, and were much smaller than those in either Heilongjiang province or South Korea. Some studies have found that
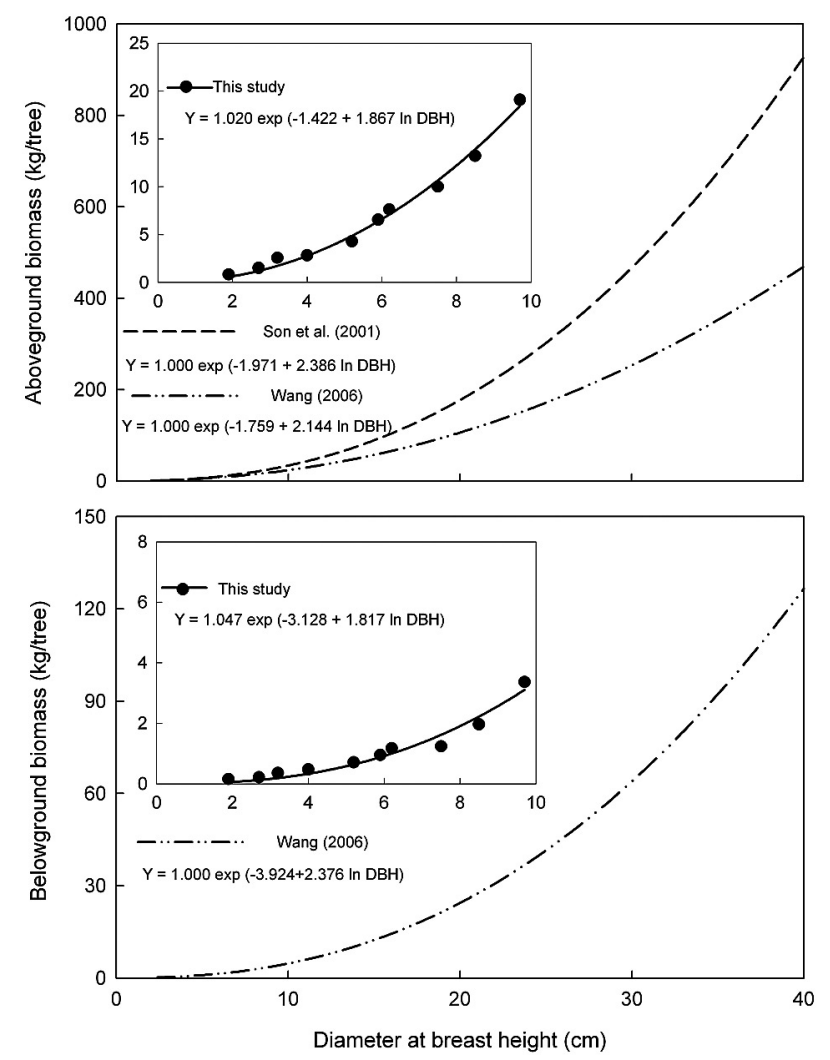

Fig. 5. Comparisons of total aboveground and belowground biomass predicted by equations in this study and previous published equations in Heilongjiang province in northeastern China and in central South Korea were made

tree biomass allometry changed with tree sizes (Niklas 1995; Litton et al. 2003; Cole and Ewel 2006). For example, Bond-Lamberty et al. (2002) reported that relationships between biomass and breast height diameter changed significantly at the breakpoint of $c a$. $3 \mathrm{~cm}$, where both slope and intercept changed dramatically, and biomass estimates using $\mathrm{DBH}$-based allometry with such a breakpoint would potentially underestimate smaller trees biomass for six boreal tree species in Manitoba, Canada. Other studies also suggested that size- or age-specific allometry may be suitable to accurately predict above- and below-ground biomass in different growth stages or in an age-sequence forests.

\section{Acknowledgements}

We thank two anonymous reviewers for their insightful and helpful comments. This research is supported by the National Special Research Program for Forestry Welfare of China (Grant No. 200904022), the $12^{\text {th }}$ five-year National Science and Technology Plan of China (2012BAC01B03) and the National Natural Science Foundation of China (31200315). Rothamsted Research receives grant aided support 
from the Biotechnology and Biological Science Research Council (BBSRC), UK.

\section{References}

Basuki T.M., van Laake P.E., Skidmore A.K., Hussin Y.A. 2009. Allometric equations for estimating the above-ground biomass in tropical lowland Dipterocarp forests. Forest Ecology and Management 257: 1684-1694.

Blazier M.A., Hennessey T.C., Lynch T.B., Wittwer R.F. 2002. Comparison of branch biomass relationships for North Carolina and Oklahoma/Arkansas loblolly pine seed sources growing in southeastern Oklahoma. Forest Ecology and Management 159: 241-248.

Bond-Lamberty B., Wang C., Gower S.T. 2002. Aboveground and below-ground biomass and sapwood area allometric equations for six boreal tree species of northern Manitoba. Canadian Journal of Forest Research 32: 1441-1450.

Brix H. 1981. Effects of thinning and nitrogen fertilization on branch and foliage production in Douglas-fir. Canadian Journal of Forest Research 11: 502-511.

Casper B.B., Jackson R.B. 1997. Plant competition underground. Annual Review of Ecology and Systematics 28: 545-570.

Cheng S., Widden P., Messier C. 2005. Light and tree size influence belowground development in yellow birch and sugar maple. Plant and Soil 270: 321-330.

Cienciala E., Černý M., Tatarinov F., Apltauer J., Exnerová Z. 2006. Biomass functions applicable to Scots pine. Trees 20: 483-495.

Cole T.G., Ewel J.J. 2006. Allometric equations for four valuable tropical tree species. Forest Ecology and Management 229: 351-360.

Crecente-Campo F., Marshall P., LeMay V., Diéguez-Aranda U. 2009. A crown profile model for Pinus radiate D. Don in northwestern Spain. Forest Ecology and Management 257: 2370-2379.

Grote R., Reiter I.M. 2004. Competition-dependent modeling of foliage biomass in forest stands. Trees 18: 596-607.

Hepp T.E., Brister G.H. 1982. Estimating crown biomass in loblolly pine plantations in the Carolina flatwoods. Forest Science 28: 115-127.

Hosoda K., Iehara T. 2010. Aboveground biomass equations for individual trees of Cryptomeria japonica, Chamaecyparis obtusa and Larix kaempferi in Japan. Journal of Forest Research 15: 299-306.

Ishii H., Wilson M.E. 2001. Crown structure of old-growth Douglas-fir in the western Cascade Range, Washington. Canadian Journal of Forest Research 31: 1250-1261.
Jagodziński A.M., Kałucka I. 2008. Age-related changes in leaf area index of young Scots pine stands. Dendrobiology 59: 57-65.

Jenkins J.C., Chojnacky D.C., Heath L.S., Birdsey R.A. 2003. National-scale biomass estimators for United States tree species. Forest Science 49: 12-35.

Johansson T. 1999. Biomass production of Norway spruce (Picea abies (L.) Karst.) growing on abandoned farmland. Silva Fennica 33: 261-280.

Lee W.K., Gadow K.v., Chung D.J., Lee J.L., Shin M.Y. 2004. DBH growth model for Pinus densiflora and Quercus variabilis mixed forests in central Korea. Ecological Modelling 176: 187-200.

Litton C.M., Ryan M.G., Tinker D.B., Knight D.H. 2003. Belowground and aboveground biomass in young postfire lodgepole pine forests of contrasting tree density. Canadian Journal of Forest Research 33: 351-363.

Mäkelä A., Vanninen P. 1998. Impacts of size and competition on tree form and distribution of aboveground biomass in Scots pine. Canadian Journal of Forest Research 28: 216-227.

McCrady R.L., Jokela E.J. 1996. Growth phenology and crown structure of selected loblolly pine families planted at two spacings. Forest Science 42: 46-57.

Mowrer H.T., Frayer W.E. 1986. Variance propagation in growth and yield projections. Canadian Journal of Forest Research 16: 1196-1200.

Niklas K.J. 1995. Size-dependent allometry of tree height, diameter and trunk-taper. Annals of Botany $75: 217-227$.

Pastor J., Aber J.D., Melillo J.M. 1984. Biomass prediction using generalized allometric regressions for some northeast tree species. Forest Ecology and Management 7: 265-274.

Petersen K.S., Ares A., Terry T.A., Harrison R.B. 2008. Vegetation competition effects on aboveground biomass and macronutrients, leaf area, and crown structure in 5-year old Douglas-fir. New Forests 35: 299-311.

Quint T.C., Dech J.P. 2010. Allometric models for predicting the aboveground biomass of Canada yew (Taxus canadensis Marsh.) from visual and digital cover estimates. Canadian Journal of Forest Research 40: 2003-2014.

R Development Core Team. 2010. R: A language and environment for statistical computing. R Foundation for Statistical Computing, Vienna, Austria. ISBN 3-900051-07-0, URL http://www.R-project.org/

Salis S.M., Assis M.A., Mattos P.P., Pião A.C.S. 2006 Estimating the aboveground biomass and wood volume of savanna woodlands in Brazil's Pantanal wetlands based on allometric correlations. Forest Ecology and Management 228: 61-68. 
Sampaio E., Gasson P., Baracat A., Cutler D., Pareyn F., Costa L.K. 2010. Tree biomass estimation in regenerating areas of tropical dry vegetation in northeast Brazil. Forest Ecology and Management 259: 1135-1140.

Son Y., Hwang J.W., Kim Z.S., Lee W.K., Kim J.S. 2001. Allometry and biomass of Korean pine (Pinus koraiensis) in central Korea. Bioresource Technology 78: 251-255.

Ter-Mikaelian M.T., Korzukhin M.D. 1997. Biomass equations for sixty-five North American tree species. Forest Ecology and Management 97: 1-24.

Van Lear D.H., Kapeluck P.R. 1995. Above and below-stump biomass and nutrient content of a mature loblolly pine plantation. Canadian Journal of Forest Research 25: 361-367.

Vanninen P., Mäkelä A. 1999. Fine root biomass of Scots pine stands differing in age and soil fertility in southern Finland. Tree Physiology 19: 823-830.

Verónica G., Luis P.P., Gerardo R. 2010. Allometric relations for biomass partitioning of Nothofagus antarctica trees of different crown classes over a site quality gradient. Forest Ecology and Management 259: 1118-1126.

Wagner R.G., Ter-Mikaelian M.T. 1999. Comparion of biomass component equations for four species of northern coniferous tree seedlings. Annals of Forest Science 56: 193-199.

Wang C.K. 2006. Biomass allometric equations for 10 co-occurring tree species in Chinese temperate forests. Forest Ecology and Management 222: 9-16.

Wang J.S., Zhang C.Y., Xia F.C., Zhao X.H., Wu L.H., Gadow K.v. 2011. Biomass structure and allometry of Abies nephrolepis (Maxim) in Northeast China. Silva Fennica 45: 211-226.

Watt M.S., Whitehead D., Mason E.G., Richardson B., Kimberley M.O. 2003. The influence of weed competition for light and water on growth and dry matter partitioning of young Pinus radiata, at a dryland site. Forest Ecology and Management 183: 363-376.

Weiner J. 1990. Asymmetric competition in plant populations. Trends in Ecology \& Evolution 5: 360-364.

Wirth C., Schumacher J., Schulze E.D. 2004. Generic biomass functions for Norway spruce in Central Europea - meta-analysis approach toward prediction and uncertainty estimation. Tree Physiology 24: 121-139.

Xiao C.W., Ceulemans R. 2004. Allometric relationships for below- and aboveground biomass of young Scots pines. Forest Ecology and Management 203: 177-186.

Zar J.H. 1996. Biostatistical Analysis. Prentice-Hall, Englewood Cliffs, New Jersey.

Zianis D., Xanthopoulos G., Kalabokidis K., Kazakis G., Ghosn D., Roussou O. 2011. Allometric equations for aboveground biomass estimation by size class for Pinus brutia Ten. trees growing in North and South Aegean Islands, Greece. European Journal of Forest Research 130: 145-160. 